\title{
SOCRATIC WALK
}

\section{EL PASEO SOCRÁTICO}

\author{
ZORAN KOJCIC \\ Sofia University \\ zorankojcic@gmail.com
}

RECIBIDO: 26 DE DICIEMBRE DE 2015

ACEPTADO: 23 DE MARZO DE 2016

\begin{abstract}
This paper aims to show the connection between beginnings of Plato's dialogues and activity which can be presented as part of philosophical practice done with individuals or groups. There are certain repetitions in Plato's dialogues at the beginnings where Socrates and other characters walk together at some point or sit together to discuss the topic of the dialogue. If we were to mimic this kind of behavior in modern day philosophical practice, we can organize interesting public gatherings and activities and call it a Socratic walk. This paper will investigate how Plato's characters conducted these walking dialogues and later present a proposition on how Socratic walk can be done with individuals and groups.
\end{abstract}

Key words: philosophy, walk, Socrates, dialogue

Resumen: Este artículo pretende mostrar la conexión ente los inicios de los diálogos de Platón y una actividad que puede presentarse como parte de la Filosofía Aplicada realizada con individuos y grupos. Existen determinadas repeticiones en los inicios de los diálogos de Platón donde Sócrates y otros personajes andaban juntos hasta cierto lugar o se sentaban a discutir algún tema por medio del diálogo. Si repitiésemos esta acción en la Filosofía Aplicada de los tiempos actuales, podríamos organizar reuniones públicas muy interesantes a las que llamaríamos paseos socráticos. Este artículo estudiará cómolos personajes de Platón animaban estos diálogos caminados para, después, presentar una propuesta de paseos socráticos entre individuos y grupos.

Palabras clave: filosofía, paseo, Sócrates, diálogo 


\section{Introduction}

For the past 30 years many different methods developed within the field of philosophical practice. Many of them were mainly influenced by or even mimiced from ancient Greek philosophers and their texts. Back then, in Ancient Greece, philosophy was different than our academic views of and scholarly approach to centuries old philosophical thought. Now that we are trying to combine ancient and contemporary methods and create philosophical activities for general public, our attention should be directed towards actions which benefit our clients and satisfy their curoius minds, just as the Greeks did with their so called pupils. Philosophical field work, which is mainly oriented to clients or participants with no academic background in history of philosophy, often shows us how general public is eager to get to know philosophical methods, which is why philosophical methods need to develop in even greater numbers. Also, many methods that already exist could be altered, taking into consideration each client's needs or needs of a group. Philosophical walks are already present in the world of philosophical practice and have been conducted in many countries around the world, also in various ways ${ }^{1}$. This paper aims to show only one of many possible ways in which walking can help philosophical practice to find its way to different clients and which is also opened to further changes.

In order to present this method, Plato's dialogues will firstly be investigated and specifically the beginnings of his dialogues, since there are certain patterns which show strong connection between walking, standing, sitting and philosophizing. After detailed overview of these verbs in Plato's dialogues, we will examine how

${ }^{1}$ Peter Harteloh in his article "Philosophical walks", Philosophical Practice, November 2013, 8.3, pp. 1297 - 1302, describes his method of philosophical walk. "A philosophical walk is a dialogue" states Hartheloh and further explains his nine steps method for individuals and groups. 
this method can be atributed to modern day participans and facilitators who practice philosophy. Combination of the two, namely Plato's writings and contemporary method will be described at the end, showing their connection and similarities with also an example of how first Socratic walks were done in Vukovar, Croatia, both with individuals and in group.

\section{Plato's dialogues}

In order to distinguish our subject in this chapter, we will mainly center our inquiry around begginings of Plato's dialogues, since this will be important for our method. As we learn more about Plato it is not hard to conclude how repetition plays an important role in his dialogues. Plato often repeats sentences or phrazes which emphasize certain messages or important thoughts. Here we should also express how mentions of walking, standing or sitting are present at beginnings of Plato's dialogues and since there are many such phrazes we can conclude that there is certain importance in how philosophizing is done according to Plato. Often, dialogues start with two or more characters asking each other where are they comming from and where are they headed (as in Menexenus, Theatetus, Protagoras, Phaedrus) or characters are mentioned as walking from certain place to another, remembering their talks with other characters or storytelling their experience to one another (Republic, Lysis, Crito, Symposion, Parmenides, Laws).

Exploring Plato's general relationship towards walking (sitting or standing) would be an important and extensive work if we were to deal with his entire opus, but in this paper we will examine only the beginnings of his dialogues in order to better mimic his method and organize it for contemporary clients and groups. In above mentioned article, Peter Harteloh states that first philosophical 
walk in western philosophy was done in Phaedrus ${ }^{2}$. However, we should emphasize that in Phaedrus, Socrates and Phaedrus are only discussing where they should sit, rest and then philosophize, they didn't actually spoke about philosophy while walking. Phaedrus first talks about the importance of walking and how it is useful for our health, as opposed to sitting in one place, since it was proposed to him by his friend Acumenus, who was a physician (Phaedrus, $227 a$ ). Socrates and Phaedrus take a walk beyond city walls, into nature where they are about to discuss love, when Socrates proposes that they find a good place to sit and talk. While walking, they talk about various things, but non of it can we call philosophizing. Even though Socrates states that he would walk all the way to Megara if needed to listen to Phaedrus' speech lead with Lysias (Phaedrus 227d), both Pheadrus and Socrates propose to sit and listen to the speech and later they only start the dialogue after they are seated, or as Socrates says, he even laid down (Phaedrus 230 e5). We conclude that the walk in Phaedrus isn't philosophical, but preparatory for a dialogue that is to take place after interlocutors are seated. Harteloh follows this example when he states that participants of philosophical walk follow the mail rule: 'we walk or we talk'3. He further explains how participants of philosophical walk need to contemplate while walking, and stand while talking to each other, since speaking distracts attention while walking. Plato, on the other hand, sometimes states different views toward philosophizing while walking. We saw how he stated Acumenus' advice on benefits of walking in Phaedrus, and at the beginning of Symposium we see how Glaucon states how talking about Socrates' dialogue on love is perfect for a walk to the city (Symp. 173b7). Apollodorus then states how they talked about Socrates' meeting with Agathon on their way and how

\footnotetext{
${ }^{2}$ See HATERLOT, op.cit.

${ }^{3}$ See HATERLOT, op.cit.
} 
philosophical talk gives him the greatest pleasure (Symp. 173c). This is where we conclude how it is indeed philosophical conversation that they had while walking to the city, but it remains unclear whether they had a dialogue, or Apollodorus only paraphrazed Socrates' speech which he was about to tell. Later in the dialogue, there is more talk of connection between walking, sitting, standing and philosophizing. When Aristodemus and Socrates meet, Socrates first replies to his question where is he going. This kind of movement verbs, as going, comming, standing, sitting are often mentioned in the following text (Symp. 174a176a) when Socrates invites Aristodemus to acompany him to Agathon's celebration, and then lags behind him, standing in neighbor's porch. Aristodemus tells the others how this is Socrates' habit, to stand motionless (Symp. 175b). Only after Socrates came in and sat down, the others begun their speeches in praze of Eros and later Socrates leads dialogue with Agathon.

Even before Phaedrus and Symposium, Plato wrote some lines of sitting while philosophizing in Theaetetus, where Euclides and Terpsion talked of Socrates and deceided to rest and listen to Euclides' notes he wrote on Socrates' talk with young Theaetetus on the topic of knowledge. There is only few statements of how Euclides and Terpsion are about to listen to a slave reading this dialogue, where Terpsion says he wants to rest after a long journey (Theaet. 143a) and Euclides proposes that they sit while the slave reads to them (Theaet. 143b). As for some of the earlier dialogues, Plato only shortly mentions distinctions between walking and sitting, as in Charmides we see Socrates returning from a battle and talking with some of his friends, when they invite him to sit down and talk about the battle in detail, while he questions them about what is happening in the city (Charm. 153d). After they present young Charmides to him, Socrates begins to question him in a dialogue, also while sitting down. In Eutidemus Crito asks Socrates 
with whom did he speak in Lyceum ${ }^{4}$ (Euthydemus 271a). We then see how Socrates was seated while he spoke with sophists, Euthydemus and his brother Dionysodorus, while the crowd listening to them stood around. Socrates states that he was sitting in Lyceum and was about to leave (Euthyd. 272e), but his divine sign appeared to him while he stood up, so he sat back again, as two brothers came in and many followers with them. After that Socrates describes how Clinias came in and sat down next to him, while the brothers were standing and talking and glancing at them. After brothers sat down, one next to Socrates and the other next to Clinias, Socrates greets them and they begin to talk. Here we also see how the mention of walking is important to Plato, but that philozophizing occurs only when participants are all seated. In Lysis, Socrates starts to talk to Hippothales, explaining to him how he walked from Academy to Lyceum (Lysis 203a), while Hippothales invites him to join him and the group of young men in new wrestling school, where they can sit down and talk to Lysis, since Hippothales is in love with Lysis (Lysis 206d). After Socrates sits down and talks to Ctesippus, Lysis sits next to them and Socrates only then starts his questioning method, which is the main philosophizing part of the meeting. We see how in some of his early dialogues Plato emphasizes that philosophical dialogue is conducted while participants are seated, but still we can conclude how preparatory walk is of importance to their talk, as almost in every dialogue participants walk from one place to another before they begin to discuss their main topics. Participants are either invited to sit down, or look for a good place to sit and philosophize. In some of his middle and late dialogues, we see how Plato changed his view on walking while philosophizing and how participants practice this form of discussion. Firstly, we can show

\footnotetext{
${ }^{4}$ It was known that Socrates spent a lot of time in Lyceum where he talked with Athenians. Later, Artistotle taught his students in Lyceum.
} 
how in Sophist Theodorus informs Socrates that they have come ${ }^{5}$ as they agreed earlier (Soph. 216a), and how stranger came with them in order to philosophize. After Socrates shows his intent to question the stranger about sophists, statesman and philosopher, Theodorus says that those are the topics they already ment to talk about to stranger as they were comming to meet Socrates (Soph. 217b5), which can only mean that they were philosophizing on their way, probably walking, even though it is not directly said. We can also compare this part of the text with previously examined dialogues, where characters firstly start to discuss the topic while walking and then the real dialogue starts after they are seated. However, in Sophists there aren't any mentions of these verbs, so it remains unclear to us how philosophizing occurs. Furthermore, in Parmenides, philosophical dialogue between young Socrates, Zeno and Parmenides is the whole reason why characters came to Athens ${ }^{6}$, as they search for Antiphon. Adeimantus and Glaucon inform Cephalus where Antiphon is and they walk to meet him, finding him talking to a smith. Antiphon informs them that young Socrates and his friends went to see Parmenides and Zeno when they came in Athens (Parm. 127b-c). After this, the dialogue between Socrates and Zeno begins and there is no more talk of walking or standing, as we can't see which was the case here, knowing only that philosophizing begun. In Republic there is a lot of mention of walking, with connection to movement verbs and also words like procession, going back, setting off, running, waiting, etc. (Rep. 327a - 328a). Socrates and Glaucon went to Piraeus for a festival, and as they headed home, they were stopped by Polemarchus' slave, after which Polemarchus demanded that

\footnotetext{
${ }^{5}$ Again at this point we see how verbs such as comming suggest walking before the dialogue takes place.

${ }^{6}$ Journey from Clazomenae to Athens also implies verbs of movement, this time long distance journey, which is needed in order to philosophize. Later on, when we examine Plato's Republic we will be able to conclude reasons for this.
} 
they acompany him in his home. When they came to Polemarchus, they found many people there, but started to talk to Cephalus, Polemarchus' father, who was offering sacrifice. Socrates and others sat down on chairs next to Cephalus (Rep. 328c). Once seated, Socrates started talking with Cephalus and Cephalus stated how Socrates should visit him more, as he (Cephalus) is old and can't walk to Athens ${ }^{7}$ any more as he used to. Cephalus also urges Socrates to visit them more, as he is more fond of conversation in old age than of physical pleasures (Rep. 328d). Socrates then tells an interesting comparison: he states that he enjoys talking to old men, as they are like travellers who have more knowledge about the path we all must walk through. This journey through life is important to Socrates, as journey one needs to pass if he wants to philosophize. Comparing this journey with previously mentioned journey from Clazomenae to Athens in Parmenides we see what is needed to philosophize - one needs to walk or journey certain lengts in order to do philosophy. Examining most of Plato's dialogues we now can conclude how almost each character must go through a walk or some other movement process in order to sit or stand and philosophize. Philosophizing, discussing certain topics with other characters, Socrates often asks them whether or not they are willing to discuss it by answering to his questions - presenting his own path, or his own walk through thinking. Even now this dialectical process we call the socratic method, where the word method also has its origins in Greek word for a path, a way.

In order to conclude this part of research, we are left only with two dialogues, which are important for our topic. Protagoras and

\footnotetext{
${ }^{7}$ If Cephalus walked from Piraeus to Athens when he was younger, we can ask whether or not Socrates and Glaucon also walked from Athen to Piraues, since at the beginning of the dialogue it is only said that they went to Piraues, not how they went there, by foot or otherwise. If we were to propose that they walked, as we see how this was Socrates' custom, we can also conclude how walking from Athens to Piraues was a preparatory walk for the dialogue as extent as Republic.
} 
Laws make important points about walking and philosophizing and Plato's approach to this topic. We have seen how in most of the dialogues, characters firstly walk and then they sit or stand and philosophize, but in Protagoras things change a bit, since we see three cases where walking and philosophizing are in close connection. In first case, at the beginning of the dialogue, Friend asks Socrates where is he comming from - same as in many other dialogues - and Socrates informs him he was with Protagoras, engaged in conversation. Friend then asks Socrates to sit down and tell him all about it (Protagoras 310a) and we see how Plato repeats this situation in many dialogues when characters first come from somewhere and then sit to philosophize together. In this case, Socrates sits down to tell his friend of his talks with Hippocrates and Protagoras. In second case, Socrates tells how Hippocrates woke him up in early morning to inform him that Protagoras has arrived in Athens and that they should visit him $($ Prot. 310c $-d$ ). Hippocrates, being younger and eager to meet with Protagoras, urged Socrates to walk right away to Callias' house where Protagora stayed, but Socrates calmed him down and said it was better to wait a bit more before they go (Prot. 311a). This is where philosophical walk occurs, for this is the first case where Socrates walks and questions any of his interlocutors for first time, stating: 'So we got up and walked around the courtyard. I wanted to see what Hippocrates was made of, so I started to examine him with a few questions' (Prot. 311b). Even though Socrates says he asked him a few question, in further dialogue we clearly read how they begun real socratic dialogue where Socrates tried to warn Hippocrates of Protagora's sophistry. Even as we can say that this dialogue with Hippocrates is preparatory for a longer one with Protagoras, we see how in this case real philosophical conversation is conducted while walking, making it possible for us to see how philosophizing is indeed possible while walking. In third case, when Socrates and Hippocrates set off to Callias' house, they stood 
in front of the house, setting an argument, before they went in (Prot. 314c). Plato then describes how hard it was for them to get to Protagoras, since a doorman at first didn't want to let them in, accusing them of being sophists. After Socrates explained that they are not sophists and that they came to see Protagoras, eunuch lets them in and they find Protagoras walking, followed by two groups (Prot. 314e). Plato then describes their movements, names some of Protagoras followers, and metaphorically states how his followers never stood in Protagora's way, litteraly following his steps probably wanting to emphasize sophist's position as the leader of the group, an authority, contrary to Socrates, who was always equal (if not pretended to be worse) to his interlocutors. Socrates then sees other people, seated at the other side of the room, describing also some who were seated on couches and beds. As he approached Protagoras and said that they came to see him, Callias proposed them to sit and discuss what they came for (Prot. 317d6). When everyone took their seat, Protagoras started to speak, Socrates followed him and so the dialogue with Protagoras begins. Again, here we see how the main discussion starts when participants are seated, so they can converse in peace. Three cases in Protagoras show us mainly what Plato has been doing in his other dialogues, but also bring new moment to our attention, a moment where Socrates and Hippocrates conduct a philosophical dialogue while walking in the courtyard. This moment is repeated in last dialogue we are about to examine, Plato's Laws. A dialogue between Athenian and Clinias reveals their clear intention to discuss the topic of constitution of laws while they are walking, as follows: '...I expect you will be quite happy if we spend our time together today in discussion about constitution and laws, and occupy our journey in a mutual exchange of views' ${ }^{8}$ (Laws, 625a). Right after

\footnotetext{
${ }^{8}$ In a Serbian edition of Plato's Laws, translation clearly states that: '..očekujem da nećete nerado raspravljati o državnom uređenju i o zakonima dok budemo za vreme naše šetnje izmenjivali svoje misli o tome' (PLATON, Zakoni, BIGZ,
} 
that, Athenian continues with saying how a long way is ahead of them (from Cnossus to Zeus' cave) and that they should find some resting places along the way, because rest is needed in their age. Clinias follows and asks '... shall we wish ourselves bon voyage, and be off?' (Laws, 625c), and Athenian confirms, right after which he directly asks a question, which means that they are finally on their way, walking and philosophizing at same time. Even though we earlier stated that this paper will deal only with beginnings of Plato's dialogues, it is important to emphasize further evidence in Plato's text that Athenian, Clinias and others are indeed all the time walking and philosophizing, which we can see when Athenian says they ought to discuss other topics to while away the journey (Laws 632e). Also, Megillus expresses his wish that their walk lasts even longer 'if some god were to give us his word that if we do make a second attempt to look at the problem of legislation...' (Laws 683c). Athenian later says 'So now, let's look into it, and while away the journey, as we said when we set out...' (Laws 685a). By these three examples, we see that characters in Plato's Laws truly do walk while philosophizing about laws, which sets a new perspective to this late dialogue.

Before our possible modern day method of socratic walk is explained, it can be concluded how Plato describes the connection between walking and philosophizing. As we saw earlier, most of his dialogues start with the description of a walk or a journey needed to pass in order to start philosophizing with little or no motion, by sitting or standing. We also see some points which may suggest that philosophical dialogue was conducted while characters were walking, but they remain unclear to us and we have no evidence in Plato's texts which situation really occured in those places. At the end, it was shown how indeed there are specific lines

Belgrade, 1971), where the word šetnja literally means a walk, replacing the word journey in English translation. 
where Plato write how philosophizing and walking is possible at the same time and his characters conduct a philosophical dialogue in even and extent text as Laws are - making it also possible for us to use this in a new approach to practice philosophical walks.

\section{Socratic walk}

After a close look at the beginnings of Platos' dialogues, we can now mimic his approach and coordinate contemporary method, which could be offered to individuals or organisations as a workshop or simply as consultations about certain issue or a topic. Each client or participant should previously be instruced in this method and think of their topic before the method is done. As Plato, we can sometimes change certain elements and conduct the walk for entire time, or we can sit down as we wish, each time doing this practice according to our clients wishes or to a better judgement. This method isn't strict or scientific and it can be changed accordingly. However, it is best to follow suggested rules and check if they fit your needs as a philosopher and client's needs. We will firstly describe the proposed method and then show how this method worked with three different clients and two groups.

In individual walks, clients are instructed to choose a topic they want to discuss, and a meeting place is earlier arranged. When we both arrive at that place, clients are asked where are they comming from (mimicing Plato), which path did they pass in order to come and philosophize, and then are asked to explain their theme. In order to take something more of Plato's writings, clients are asked to tell a story (mythos) about their topic - why did they choose that topic, to which of their experiences is the topic related, what is their issue with the topic and which segment of the topic they want to question. During this introductory talk, philosopher and client walk along previously arranged path or sometimes at random, but always 
having in mind one place they should later sit - in order for method to follow Plato's main dialogues. The walk should last for about 20 to 30 minutes, if we are to sit later, whereas dialogue during sitting can last for about an hour. Within that time, philosopher and client should question the topic, make main points and discuss the topic in detail during socratic dialogue, especially if they are seated. During the walk, clients should talk more, whereas philosophers can ask certain questions, make comments or propose ideas, but their main focus should be to get to know the client, and remember main concepts which clients mention. After this introductory exchange of ideas, both of them should find a good place to sit and engage in socratic dialogue. Clients can be asked to undergo different philosophical approaches to certain subject, such as argumentation, conceptualization, induction or deduction, or any other, but asking of them to simplify their views demands an effort they can use for further dialogue. Therefore, I suggest to ask clients to conceptulize the walk and their mythos, which was said earlier, during the walk. Clients can conceptualize the talk in a word, or in a sentence, or both, after which they should ask a question about the topic. When they ask a question, we can engage in a dialogue, where philosopher asks further questions while clients answer them. This approach unfolds in two ways. First, allowing clients to express themselves through storytelling (mythos) at the beginning gives them comfort, since they are used to one way communication, where they speak about their problems and the other side listens. This is where they feel comfortable and in their own field. Later, this position is challenged by the dialogue (logos), which then shows them where the real work is done - in relation to other and when the other (philosopher) has an insight into their issues. The other asks questions and provoques thinking which we wouldn't dare to do on our own or we would carefully dodge. Philosophizing occurs only during the dialogue, but mythos was 
also important to Greeks and many philosophers allowed it to happen only to prove logos to be more important in truth seeking. In a group philosophical walk, participants are asked to come to a meeting place in a city or in nature. When everyone arrive, they are asked to share where are they comming from (mimicing Plato) in order to share which path they took, what led them in life toward philosophizing that particular day or generally in life. Instructions are given to participants - each participant recieves a paper with a provocative sentence which is a statement about a certain topic. The topic is mostly about philosophical issues, whether in metaphysicis, ethics, epistemology or any other field of philosophy, and is related closely to both ancient or contemporary issues. After that, participants should walk in pairs, conducting a dialogue about the issue they were given. The walk lasts for about 30 to 40 minutes and is only preparatory activity for the main discussion, where participants are seated (as in Plato's dialogues) at a cafe, a park or any other convenient venue. During the walk, participants are instructed to question and examine the statement they choose they should each express their own opinions and views, ask each other questions and give answers, share their experiences about that topic and take into consideration time they were given. They should not rush things, they should not give any quick solutions, but in half an hour time they have a chance to thoroughly examine given topic. In philosophical walk by Peter Harteloh, participans follow the philosopher (facilitator) on a predestined route in silence, contemplating their concepts, quotes and ideas. In Socratic walk participants are encouraged to walk their own way for half an hour and then come to the meeting point to sit and discuss their topics. Reason for this is that following philosopher resembles mostly that scene in Plato's Protagoras described above, where students follow Protagoras almost exactly in his footsteps, meaning as if they don't think for themselves anymore, but are preocupied with what their teacher, namely the sophist Protagoras, is doing. Of 
course, I don't claim that it is the same case in Harteloh's method, I argue that it is better to let participants wander around on their own - of course, if we know all participants are responsible adults engaged with the problem they were given. In this way they are more responsible and more connected to their peer. Participants should be instructed about a meeting place after half an hour walk, where they should all gather for main discussion. Main discussion begins when everyone arive at the venue where each pair will share their sentences and what they discussed during the walk. After participants share their stories in pairs (mythos), others are encouraged to ask them questions, give comments and express their own views about the topic, thus creating several shorter discussions about each of the topics. Facilitator can make sure that the discussion doesn't go off topic and that participants keep the discussion within the field of philosophy, where many other different methods can be applied. Of course, it is much easier to keep questioning in philosophical discourse when the dialogue is between single client and philosoper. Facilitator therefore must make sure to aim their sentences to be as close to philosophical issues as possible.

At this point three individual Socratic walks will shortly be described. All three clients were instructed to think of a topic for our walk and conversation and they were instructed how the method works. First walk was with a client Dunja ${ }^{9}$. We met in front of her house and started walking imidiately as I first repeated the rules and she stated that she couldn't think of a specific topic, but started her talk about presidental elections which were about to take

\footnotetext{
${ }^{9}$ All three clients were instructed to choose different names than their real ones, in order to maintain anonimity. Client Dunja had a degree in philosophy, client sir Oliver had a degree in theology and both of them had previous experience with some methods of philosophical practice, while client Interrupted with a degree in information sciences didn't have any experience with philosophical practice before.
} 
place ten days after our walk. In this preparatory walk, clients are encouraged to express their issues, problems, thoughts, ideas, questions about the topic they choose. This is where we allow mythos to come out and clients present their worldviews or main points about the topic. At the same time, we allow certain Platonic instance (myth, story) to speak for itself and also we get to meet client's thoughts and the way of thinking, but as philosophers we also participate in their story by asking further questions when we see there are flaws in their story, or if we are interested in their approach at any point. At first, Dunja only spoke of how she doesn't really have the freedom to choose between presidental candidates as both of them aren't of her liking for many reasons, but then she flipped her story toward more general problem, which for her was both general and personal pessimism. Our walk lasted for about a half an hour, where my role as philosopher was to ask questions when I saw it was needed to encourage her to express her points and thoughts about the topic. Dunja's role was to answer those questions in broader terms and to form smaller stories which would explain her worldview. As in Plato's dialogues, we didn't get into dialogue while we were walking, but only after we sat down in this case for a coffee at a cafe nearby. After we were seated, Dunja's first task was to conceptualize her mythos. She did it first with one sentence, which was Pessimism can be an encouragement for possitive change, and a bit after that she conceptualized our previous talk with one word, which was pessimism. In order to continue our method, after we were seated, Dunja's task was to start our dialogue with a question she had about her mythos and she simply asked How can one use pessimism as an encouragement for positive action. The main aim of our further socratic dialogue was to explore Dunja's question and if possible to find an answer for this question, to find the truth. After about an hour of socratic dialogue in which we questioned her views and forementioned concepts, Dunja came to conclusions related to those concepts and 
found the solution in combining knowledge and belief as two major oppositions. After our dialogue, she stated that walking and philosophizing can be rewarding and that she was satisfied with the method.

I met my second client, sir Oliver in front of his building and asked him where did he come from, in order to mimic Plato's approach to Socrates' interlocutors, but I also added the questions what were his previous encounters with philosophy, in order to present him the idea that a path is needed to cross so one can philosophize. After answering those questions, sir Oliver stated that he wanted to test philosophical practice with really practical question of how to obtain more money. So, as we walked (for about 30 minutes) I questioned him on how much money is enough for a person to obtain and whether or not anyone is really satisfied with any ammount of money they can obtain. Questioning this concept, we also talked abut happines and personal satisfacion, where sir Oliver, just like Dunja, presented his mythos, his story and the view on the given topic. During our walk, we switched from very concrete demand on obtaining more money, to more general questions about life. After our walk, we sat down in my apartment, and sir Oliver was instructed to conceptualize our talk. Firstly, he gave a one word concept of satisfaction, as the main topic of our discussion and his mythos. After that, he stated his sentence about our walk as Just one pleasant walk, and later on he said that his question for our socratic dialogue is How can I satisfy myself. After that we went back to his claims about the money where he concluded that he wanted to do less intellectual and more physical work. He illustrated an example of a monk who liked to play football, but who said that when one is about to score, one should not think (contemplate), but one should kick the ball (act) and score or miss. In a dialogue later on we questioned this approach and compared sir Oliver as person who should act more, but he stated that he was affraid of it. At the end of our dialoge, he stated that he 
can satisfy himself by doing something, acting, which is often risky. We concluded that philosophical practice failed his little test with practical question (how to obtain more money) but only provided him with more questions, which further led us to state how philosophical practitioners can't answer their client's questions and can't solve their problems, they can only guide their clients to clear their thoughts and find the solution for themselves.

Third client in Socratic walk was, as she stated, Interrupted. I met her in her street where she stated she was comming from her apartment and that she was interested in Socratic walk because it was new to her and it seemed interesting. Interrupted stated she has an issue that is bothering her, after which she begun to tell her mythos. We walked for almost an hour, during which she told me of her past relationship and problems she had with her ex boyfriend. Her story was coherent enough and she told it from the beginning untill the end with much passion and emotions. I listened to her carefully and tried to pick up her thoughts and feelings, connecting certain concepts and ideas. During the walk I asked her to conceptualize her story. At first, she choose experience as her one word concept, but few seconds later she changed her mind and said that concept of milestone would also fit her story. Later on, she could not conceptualize the story in one simple sentence, as she felt it would trivialize the story which is stil a big part of her life. After that, we started socratic dialogue and her main issues came to surface - she acknowledged that she doesn't know what she wants of her life. We continued our talk in a local cafe and after we were seated, she formed a question about her story as follows: Why did I persist to get back to him when he had constantly hurt me. During our dialogue, Interrupted showed less confidence compared to our walk, when she was allowed to freely express her mythos. When confronted to series of questions, which often demanded short answers, she was reluctant to form simple sentences and to connect the facts logically. We came to conclusion that she has issues with 
choosing and taking responsibility for choices she makes. Not knowing what she wanted of her life was also connected to childish behaviour, which should culminate in future, when she needs to deceide between immature, but exciting and mature, but rational relationship. No matter which path she chooses, she thinks she will feel regret. She realized she has issues with simplification, which leads to childish behaviour and insecurity. We ended our dialogue without concrete solution and answer to her question, but we concluded that this is something she needs to figure out on her own. Interrupted stated that she finds Socratic walk useful, because it helps a person to find himself/herself, face their problems and strenghten their views, and that she would definitely do it again. Later on, she wrote to me that she even recomended Socratic walk to some of her friends.

In each case, clients expected something different then what they got at the end. We can speculate why is this the case, but at this point we need to focus on critique that this method can face in future. Firstly, as a philosopher, I must agree with Harteloh's claims that walking and philosphizing isn't a tourist tour, but an activity which demands enormeous effort for both client and a philosopher. Philosopher needs to be fully prepared to listen and remember all major points of client's story, main concepts and worldviews, ideas and key points around which our client builds their story. It is hard to walk and make notes, so active listening plays a vital role during the walk. Of course, philosopher is allowed to ask questions or demand clarification, to observe and to challenge client's mythos. This mythos is important for our clients because this is where all the problems are hidden and clients live by those notions which block their logical strain of thought which could easily lead to solution. Surely, we are as human beings also subjected to our emotions and we tend to mix emotions into our mythos, making it comfortable place to stay. Plato also used myths in his dialogues in order to prove a point or to illustrate certain ideas, also to bring his 
thoughts closer to people who were unable to follow logos. Logos is the place where philosophy happens, the true search for wisdom. This is why, in Socratic walk, I want to confront those two sides within my client. Firstly, I will provide them with thier own story, to express it clearly and in which ever way they want, during which I will pick up main issues, concepts, worldviews and ideas, after which they will engage in $\log o s$, reason, questioning, in a dialogue exactly about those concepts hidden in their story. Second reason for this order is in Plato's dialogues, where seemingly trivial conversation usually takes place during the walk and real philosophical dialogue takes place after interlocutors are seated. This differentiation can also be connected with many of Plato's oppositions, whereas walking is connected to mythos, something which isn't still, which moves, which is impermanent, and sitting is connected to logos, which is still, permanent, stable, constant.

In group Socratic walk, rules are somewhat different. As stated before, the group should be introduced with clear ruels before the beginning, given by facilitator, a philosopher. For the purpose of this article, two group Socratic walks will be described, conducted in Croatia, first in April 2015, for high school philosophy teachers during the National competition in philosophy for high school students, and the second for participants of first Philosophical Practice Summer Weekend in July 2015. In both cases the rules were the same, but due to practical reasons were not as same as previously instructed in this paper. Main suggestion is for a facilitator to give instructions to the group and divide them into pairs, which would spend about half an hour walking and leading a dialogue about the sentence they were given. Participants should never follow facilitator strictly, but they are to be given a path or plan of the walk and to walk at their own pace or route, which is best to be circular around the meeting place, in order not to look like sophists blindly following their teacher, this way encouraging participants' creativity and freedom. Unfortunately, due to not 
knowing the area very well, because in both cases participants were not from the city where the walk was conduced, they followed the facilitator, but at their own pace, for about a 30 minutes walk. During the walk they discussed some of the following sentences:

The body is mortal, the soul is eternal and imperishable. In not so distant future, machines will become dominant beings in our world. God makes all things good, but man is the one who destroys them. We can know ourselves, we can change, we can make new habits, we can create richer lives for ourselves.

These sentences should make a claim, in order for clients to express their opinion on them and to lead a dialogue. They may or may not agree with them, it is their task to show it and to provide an opinion, backed with arguments, examples and further questions which can prove their point or abandon it in a dialogue with them other participant. Each pair is given only one sentence and they lead a dialogue about it during the entire walk. Their dialogue is introductory for the main discussion which is lead after the walk, when everyone is seated. Depending on time and the number of participants, facilitator sets the rules on which pairs get the chance to share their walking and dialogue experience with the rest of the group. When everyone is seated in a arranged venue, facilitator asks participants to share their sentences and then what was their dialogue about, which were the main difficulties and which were the conclusions the pair got out of it. After the pair tells their mythos, other participants are welcomed to join in and ask questions, share their thoghts or provide new insights and arguments, depending on time (which can be for about ten minutes for each pair, if there are up to 15 participants, which could be an optimal number). After participants are done with their discussion, or after the time is up, the discussion can be concluded with various methods, but for the two cases in Croatia, here presented, method of conceptualisation was implemented, where each participant 
stated one concept about the entire workshop, and later on, in meta discussion about the workshop also stated their satisfaction with combination of walking and philosophizing, as well as with the possiblity to discuss other pairs' topics. We can also see how in group workshop style Socratic walk we follow similar principles as Plato does in dialogues. We set on a preparatory walk, where participants engage in dialogue about chosen topic, and after the walk, they are all seated and engaged in group discussion with a socratic method in mind.

\section{Conclusion}

By investigating the beginnings of Plato's dialogues it quickly becomes clear to us how a pattern is often present in his approach toward the connection between walking and philosophizing. Having recorded the socratic method for us, Plato can serve as a good example on how to implement this method in contemporary philosophical practices and following his footsteps, this paper tries to show a possible way to work with given method with modern day clients. Philosophical practices such as philosophical counselling and philosophical cafes were among most popular in last two decades, while today we can investigate whether philosophical walks can be of any use to us and our clients in order to achieve main goals of philosophical practice.

Other than following ancient advice, put in a mouth of previously mentioned Acumenus, naimely that walking is good for health of our body, we can now also imply how walking can be good for health of our mind, if we engage in philosophical dialogue while we are walking. By acknowledging that this task isn't an easy one, we should consider both positions, that of a counsellor and that of a client, if we wish to engage in this activity and suggest it to others. Both on an individual plan and in a group approach, 
certain rules should be respected and both parties should stick to those rules, usually led by a philosopher. By proposing rules similar to the behaviour of characters in Plato's dialogues, we might aim at achieving the similar goal - investigating path toward truth and wisdom.

Individual Socratic walk, in which clients firstly speak about their mythos while walking for half an hour and then sit for the rest of socratic dialogue, has show in several cases as useful for clients in questioning important life issues and dealing with those questions in a different way. Having the chance to first express their point of view, no matter how confusing or disorderly, gives clients a glance at the true purpose of a dialogue and clarity it can provide. This should not be considered as missleading, giving them a chance to express their views and then turning them back to dialogue, but should be considered as an introduction to dialectic and an opportunity for reasoning, which later occurs. Rationally, we know that our clients think about their problems and are dealing with them in some manner, so our job as philosophical counsellors is to investigate this not only by questioning them, but also by using other methods to do so. If we can see their strain of thoughts which they usually use to deal with this problem, and which we see during half an hour walk and which we follow and later can use in a dialogue, we are to better evaluate these issues and deal with it as a helping tool to eventually solve the problem. Also, during Socratic walk as a group workshop, firstly we get the chance to investigate several interesting topics during the walk, where we meet our pair and engage in a dialogue with them, just as Socrates' students had the chance to do with him and other pupils, by which we prepare for the real work. The only difference here is that we don't listen to one teacher, but we are all allowed to participate and contribute to a discussion equally as others. As a workshop, Socratic walk combines two major activities popular in philosophical practice - principles of which are based on individual 
socratic dialogue and philosophical cafe. Both approaches should, by all means, countinue to be tested and investigated by practitioners and if proven to be useful and helpful in practice, as they have so far, Socratic walk, together with some other similar practices, might bring fresh approach into the field.

\section{References}

PLATO, Complete works, Hacket Publishing Company, Indianapolis/Cambridge, 1997

PLATON, Zakoni, BIGZ, Beograd, 1971

HARTELOH, Peter: "Philosophical walks",Philosophical Practice, 8.3., November 2013, pp. 1297 - 1302 